\title{
THE ETIOLOGY OF SPECIFIC PHOBIAS: A REVIEW
}

\author{
Harald Merckelbach, Peter J. de Jong, Peter Muris, and \\ Marcel A. van den Hout
}

Department of Experimental Abnormal Psychology, Limburg University

\begin{abstract}
The present article summarizes theory and data about symptomatology, epidemiology, and etiology of specific phobias. Additionally, the cognitive mechanisms involved in specific phobias are briefly discussed. By and large, the general pattern behind the development of specific phobias can be summarized as follows. Specific fears are highly prevalent among young children. In most children, these fears represent transitory phenomena. However, in a small subgroup of children, specific fears become chronic due to classical conditioning, modelling, and/or negative information transmission. Once a specific phobia has developed, it may be maintained by cognitive biases (i.e., attentional bias, covariation bias, and reasoning bias). Though specific phobias form a heterogeneous class of disorders, this pattern appears to be a good approximation. Nevertheless, several questions remain. For example, there is no ready explanation for the fact that specific phobias are more often diagnosed in women than in men. Similarly, it is not clear to what extent the nonrandom distribution of phobias can be interpreted in terms of cultural factors. Resolving these issues is not only important in its oun right, but may have considerable heuristic value for our understanding of other anxiety disorders.
\end{abstract}

SPECIFIC (formerly "simple," "monosymptomatic," or "focal") phobias are irrational and persistent fears of certain objects or animals. Whereas the concept of "specific phobia" is relatively recent, the condition to which it refers is not (Errera, 1962). For example, Hippocrates described a man displaying an irrational fear of bridges. Likewise, detailed discussions of phobic symptoms can be found in the work of 17th and 18th century authors such as Descartes, Le Camus, and Sauvages.

Although descriptions of phobic behavior have remained remarkably consistent throughout history, theories purporting to explain this behavior have changed dramatically. In early medical texts, speculations about eye muscle dysfunction, vascular abnormalities, or mysterious underground water streams were not uncommon (Errera, 1962). During the past decades, our understanding of the origins of specific phobias

Correspondence should be addressed to Harald Merckelbach, Department of Experimental Abnormal Psychology, Limburg University, PO Box 616, 6200 MD, Maastricht, The Netherlands. 
has steadily increased. It is now recognized that learning mechanisms and developmental processes play a crucial role in the etiology of specific phobias. Furthermore, the available evidence suggests that certain cognitive processes contribute to the maintenance of phobic symptoms. The present paper evaluates these elements in more detail and is structured as follows. In the first section, the symptomatology and epidemiology of specific phobias is considered. The second section focuses on developmental aspects of specific phobias. This is followed by a discussion of the learning mechanisms that are involved in the etiology of specific phobias. The fourth section then outlines various cognitive mechanisms that presumably intensify phobic symptoms. The fifth and final section summarizes the main points of this paper.

\section{SYMPTOMATOLOGY AND EPIDEMIOLOGY}

\section{Symptomatology}

The Diagnostic and Statistical Manual of mental disorders, fourth edition (DSMIV; American Psychological Association [APA], 1994) lists three central features of specific phobias: (a) fear is directed at a limited set of stimuli, (b) confrontation with these stimuli elicits intense fear and avoidance behavior, (c) the fear is unreasonable and excessive to a degree that it interferes with daily life. These characteristics deserve comment.

As for the first feature, survey studies (e.g., Agras, Sylvester, \& Oliveau, 1969; Costello, 1982) have consistently found that, in the general population, some fears (e.g., fear of snakes) are far more prevalent than others (e.g., fear of electricity). Likewise, factor analyses of normal subjects' responses to fear questionnaires indicate that the most prevalent fears can be grouped together in a relatively small number of distinct categories (Arrindell, Pickersgill, Merckelbach, Ardon, \& Cornet, 1991). In other words, fears and phobias typically pertain to relatively narrow and circumscript classes of stimuli. Seligman (1971), Ohman (1986), Marks (1987; Marks \& Nesse, 1994), and Menzies and Clarke (1995) have interpreted this phenomenon in evolutionary terms. According to these authors, the stimuli feared by phobics reflect the dangers that our prehistoric ancestors faced in their Pleistocene savannah environment. As a result of natural selection, fear of these evolutionary dangers became genetically coded. Consequently, modern man would still possess an innate tendency (Menzies \& Clarke, 1995) or preparedness (Seligman, 1971) to develop fear of spiders, snakes, blood, etc. Although these evolutionary accounts have attracted considerable attention (see below), other interpretations of the selectivity of fears do exist. For example, the selectivity of specific fears may be a consequence of the negative connotations that certain stimuli have in our culture (e.g., spiders are commonly seen as dirty; see Davey, 1995). Whatever its cause, the nonrandom distribution of specific fears is a robust phenomenon. In fact, DSM-IV (APA, 1994) differentiates between four highly prevalent types of specific phobia, namely: animal type (e.g., spider phobia), natural environment type (e.g., phobia of heights), blood-injection-injury type (e.g., dental phobia), and situational type (e.g., claustrophobia). In addition, DSM-IV introduces a miscellaneous category ("other type") which encompasses, for example, choking phobia. The DSM-IV categories are in general agreement with a recent study by Fredrikson, Annas, Fischer, and Wik (1996). Their factor analysis of specific fears and phobias confirmed that animal phobias and blood-injection-injury phobias represent separate categories. However, these authors also found evidence to suggest that the situational and natural environment phobia type cluster together and possibly "share a common underlying theme" (Fredrikson et al., 1996, p. 37). 
The second feature of specific phobias (i.e., intense fear and avoidance) raises questions about the nature of these phenomena and about their relationship. A good framework for discussing this point is the "three-systems-model" proposed by Lang (1968; see also Hugdahl, 1981). According to this model, fear is reflected in autonomic symptoms (e.g., tachycardia, increased respiration, etc.), subjective feelings of apprehension, and avoidance or escape behavior. However, the extent to which these components cooccur varies (Hugdahl, 1981, 1989). The three-systems-model has important implications for the study of specific phobias. To begin with, the model suggests that in diagnosis or therapy outcome evaluation, each component should be independently assessed. This point seems self-evident, but, as a matter of fact, studies in this area often either rely on one or two measures or make use of vague and imprecise instruments to tap the three components (Eifert \& Wilson, 1991).

Not all types of specific phobias display a comparable profile with regard to the three components. For instance, both animal phobia and blood-injection-injury phobia are accompanied by subjective reports of distress. However, whereas in animal phobia distress usually takes the form of fear (but see Matchett \& Davey, 1991), bloodinjection-injury phobia is associated with strong subjective feelings of disgust and repulsion (Page, 1994). Also, confrontation with the phobic stimulus elicits sympathetic activation (e.g., tachycardia) in animal phobia, but a biphasic response pattern (i.e., initial tachycardia followed by bradycardia; Page, 1994) in blood-injection-injury phobia. That is, while exposure to the phobic stimulus produces heightened arousal in animal phobics, lowered arousal that may result in fainting is seen in blood-injection-injury phobia (Thyer, Himle, \& Curtis, 1985; Marks, 1988). Referring to these peculiar characteristics of blood-injection-injury phobia, Rachman (1990b) has argued that the term blood-injection-injury phobia is a misnomer. According to Rachman, blood phobics do not fear blood. Instead, blood phobics fear the consequences of confrontation with blood (e.g., fainting). This would imply that there may be an interesting connection between blood-injection-injury phobia and panic disorder. In both conditions, fear of bodily sensations plays an important role; however, the DSM-IV treats blood-injection-injury phobia as a specific phobia.

As far as the content of subjective fear is concerned, there are also major differences between situational phobia, especially claustrophobia and animal phobia. Subjective fear in claustrophobia is not only focused on danger (e.g., fear of suffocation), but also on anxiety expectancies (e.g., fear of going crazy) and bodily sensations. The latter components are less prominent in animal phobias (Craske, Mohlman, Yi, Glover, \& Valeri, 1995). Thus, from a cognitive point of view, claustrophobic fear seems to be a more complex phobia than animal fear. Indeed, a close look at the subjective cognitions that are involved in specific phobias makes clear that these phobias do not constitute a homogeneous class (Himle, Crystal, Curtis, \& Fluent, 1991).

The third characteristic of specific phobias that requires some comment is their alleged irrational nature. The patient suffering from, say, an intense spider phobia readily admits that her or his fear is excessive. Nevertheless, she or he is unable to inhibit fear responses when exposed to spiders. Some authors have argued that the standards of rationality do not apply to phobic fear reactions, precisely because they are involuntary. In McNally's (1987) words: "Like a toothache, physiological fear responding is nonrational rather than irrational. Toothaches and racing hearts have causes, they do not have reasons" (p. 297). Other researchers have suggested that while the patient is convinced of the irrationality of the phobia when questioned in the absence of the feared cue, the presence of this cue may activate idiosyncratic danger expectations. Support for this line of reasoning comes from a study by Arntz, Lavy, 
van den Berg, and van Rijsoort (1993). These researchers had spider phobics rate how much they were inclined to believe highly unrealistic propositions about spiders when confronted with spiders. Data indicated that in the presence of their feared object, spider phobics report various catastrophic believes about the spider (e.g., "the spider will attack me") and about their own reactions (e.g., "I will go crazy"). A recent study by Thorpe and Salkovskis (1995) confirmed this finding for a wide range of specific phobias. It should be acknowledged, however, that neither Arntz et al., nor Thorpe and Salkovskis made a direct comparison between phobics' beliefs in the absence and in the presence of their feared object.

A somewhat different stance is taken by Öhman (1993) who argucs that phobic stimuli are analyzed by fast and subcortical information processing routines. These information processing routines would provide a crude analysis of the stimulus and then initiate an immediate fear response. Consequently, even before the person becomes fully aware of the phobic stimulus, a fear response is already on its way. This may explain why phobics experience their fears as uncontrollable. The fact that phobics do have unreasonable danger expectations when confronted with the feared cue (Arntz et al., 1993) may reflect a post hoc tendency to "rationalize" an experienced fear reaction. Indeed, there is evidence that fearful subjects tend to infer danger from fear: "if I am frightened, than there must be danger" (Arntz, Rauner, \& van den Hout, 1995).

Support for Öhman's hypothesis (1993) comes from a study in which it was shown that subliminal presentations of phobic slides (i.e., spiders and snakes) are sufficient to elicit autonomic responding in phobic but not in control subjects (Ōhman \&c Soares, 1994). This finding fits well with the animal studies of LeDoux (1992). This researcher found evidence for a subcortical fear pathway linking the thalamus with the amygdala. The thalamo-amygdala pathway is a "quick and dirty" transmission route in which the thalamus carries out a crude analysis of the sensory input and then activates the amygdala, which, in turn, generates an emotional response. According to LeDoux (1992), this pathway has adaptive value:

the thalamo-amygdala system might be especially useful as a processing channel under conditions where rapid responses are required to threatening stimuli. In such situations, it may be more important to respond quickly than to be certain that the stimulus merits a response. (p. 276)

Thus, one may speculate that, in specific phobia, learning experiences have affected the thalamo-amygdala pathway in such a way that it is oversensitive to certain phobic cues.

Interestingly, in their PET scan studies, Fredrikson and associates (Fredrikson et al., 1993; Fredrikson, Wik, Annas, Ericson, \& Stone-Elander, 1995; Wik, Fredrikson, Ericson, Eriksson, Stone-Elander, \& Greitz, 1993) demonstrated that provocation of specific phobias through visual stimulation is accompanied by distinct changes in cerebral regional blood flow (rCBF). In accordance with LeDoux's (1992) proposal, these authors found in one of their studies (Fredrikson et al., 1993) clear indications that the thalamus functions as an important relay station for phobic stimulus processing. Yet, the most consistent finding that emerges from their work is that phobic provocation is related to increased neuronal activity in the secondary visual cortex and decreased activity in the paralimbic and prefrontal areas (Fredrikson et al., 1995; Wik et al., 1993). Fredrikson and coworkers argue that the increased activity in the secondary visual cortex reflects increased and externally directed vigilance, while the decrease in paralimbic and prefrontal activity reflects reduced conscious, voluntary processing and preparation for automatic defense. Clearly, this pattern is more complex than the 
model proposed by LeDoux (1992). However, further studies are needed to establish a more definite picture of the neuroanatomic underpinnings of specific phobias.

\section{Prevalence, Natural Course, and Genetics}

Epidemiological evidence indicates that phobias may affect more than $12.5 \%$ of the general population (e.g., Myers et al., 1984; Regier et al., 1988). This suggests that phobia is one of the most common mental disorders. As far as the more restricted category of specific phobias is concerned, the recent National Comorbidity Survey of Kessler et al. (1994) found lifetime prevalence and 12-month prevalence rates of $11.3 \%$ and $8.8 \%$, respectively. Thus, the prevalence of specific phobias is high and there are reasons to believe that this is also true for non-Western societies (e.g., Hong Kong; Chen et al., 1993).

In his community study among women, Costello (1982) found that animal fears (including fear of dogs, snakes, etc.) were the most prevalent, followed by nature (e.g., heights), and mutilation (e.g., injections) fears. Whether these fears represent clinical phobias is questionable. Using DSM-IV derived criteria for specific phobias, Fredrikson et al. (1996) found that situational and environmental phobias had the highest pointprevalence rate (i.e., $13.2 \%$ ), followed by animal phobias, and blood-injection-injury phobias (with point prevalence rates of $7.9 \%$ and $3.0 \%$, respectively). Another robust finding in survey studies is that most specific phobias are diagnosed more often in women than in men (e.g., Myers et al., 1984; Chapman, Fyer, Mannuzza, \& Klein, 1993; Fredrikson et al., 1996). This is especially true for animal phobias (Sturgis \& Scott, 1984; Öst, 1987; Kirkpatrick, 1984) and situational and environmental phobias (e.g., Fredrikson et al., 1996), but less so for blood-injection-injury phobias (e.g., Fredrikson et al., 1996). Sex differences in the prevalence of specific phobias cannot be explained fully by assuming that it is more socially permissible for women to report fear than for men (Cornelius \& Averill, 1983). Such a simple self-report bias account is unable to account for the balanced sex distribution of blood-injection-injury phobias (Fredrikson et al., 1996). Furthermore, this account is difficult to reconcile with the findings of Speltz and Bernstein (1976). These authors showed that snake fearful men behaved less fearfully on a Behavioral Approach Task (BAT) than their self-report would indicate. Speltz and Bernstein (1976) also demonstrated that under a high demand condition (i.e., social pressure), approach behavior of women reached a similar level as that of men under a low demand condition. These findings suggest that for men, social pressure to interact with feared situations has a prophylactic effect. By the same token, socially embedded sex-roles might be an important vulnerability factor in women (see also Chambless, 1988). Possibly, other predisposing factors (e.g., sex hormones; see below) also play a role in the skewed sex distribution of some specific fears and phobias.

While specific phobia appears to be a highly common disorder in the general population, treatment seeking is relatively rare. Chapman and coworkers (1993) compared treated and untreated individuals with specific phobia. These authors concluded that patients who enter treatment programs differ from untreated individuals in that they more often have multiple phobias and/or phobias that are complicated by panic symptoms.

As for the natural course of specific phobia, Wittchen (1988) summarized the results of his longitudinal community study as follows:

The natural course of simple phobias is in the majority of cases chronic and can be characterized by the persistence of mild rather than severe symptoms of anxiety over decades. 
Only $16 \%$ remitted completely over the follow-up period of 7 years: thus, only very few spontaneous remissions could be observed. (p. 14)

Several large scale twin studies have explored to what extent genetic factors predispose to phobic fear (e.g., Kendler, Neale, Kessler, Health, \& Eves, 1992). Briefly, these studies have found that the genetic contribution to specific phobias is modest though significant. Moreover, the genetic factors underlying specific fears appear to be of a general nature, which means that there is inheritance of a general trait that predisposes to neurotic complaints rather than inheritance of a specific fear. Thus, in some cases, the predisposition is expressed as a specific phobia, and in other cases the complaints may take the form of, for example, social phobia, agoraphobia, and so on (Andrews, Stewart, Morris-Yates, Holt, \& Henderson, 1990; Philips, Fulker, \& Rose, 1987). Blood-injection-injury phobia may represent an exception to this pattern. There is some evidence suggesting that in blood phobia, the genetic contribution is fairly specific (Marks, 1988). In line with this, Stevenson, Batten, and Cherner (1992) found, in their study of common fears in twins aged 8-18, a substantial heritability for fear of injury and small animals. Unfortunately, these authors did not assess the separate heritabilities for fear of injury and fear of animals.

\section{DEVELOPMENTAL ASPECTS}

In general, specific phobias have an early onset. For example, Öst (1987a) reported mean onset ages of 7 and 9 years for animal and blood-injury-injection phobias, respectively. An early onset is also found in natural environment phobias. Thus, a considerable percentage of height fearful subjects report that their fear has always been present (e.g., Menzies \& Clarke, 1993a) and much the same seems to be true for water phobia (Menzies \& Clarke, 1993b). However, claustrophobia differs from this pattern in that it has a later onset. Öst (1987a) reported a mean onset age of 20 years for his sample of claustrophobics. This late onset accords with the impression that claustrophobia is a more advanced fear, when one looks at the cognitions that are involved. Nevertheless, by and large, a substantial proportion of specific phobias begin in childhood. This finding is underlined by surveys of subclinical fears among children. In an early study of MacFarlane, Allen, and Honzik (1954), it was found that only a small minority of a large sample of children $(N=1,096)$ displayed no fear reactions. A similar result was reported by Lapouse and Monk (1959). These authors found, for example, that in 6-8 year olds, nearly $44 \%$ have a mild fear of blood. Thus, mild to moderate fears are commonplace among younger children. In this connection, there are several points that deserve comment.

Firstly, studies evaluating specific fears in children have generally found that girls report more fears than boys (Ollendick \& King, 1991; Stevenson et al., 1992). However, there are also indications that gender differences are modulated by age. For example, MacFarlane et al. (1954) reported that girls display more intense fears than do boys only after age 11 . Secondly, the mild fears seen in children often seem to appear and disappear spontaneously. Thus, they are transient developmental phenomena with a predictable course (see, for an extensive discussion, Marks, 1987). For example, Bauer (1976) found that fear of ghosts and fear of animals are common in children aged 4-8. In contrast, fear of injury is more characteristic of children aged 10-12. According to Bauer, these fluctuations are closely tied to cognitive development. Younger children would rely on global perception and animistic concepts in interpreting cause-effect relationships. This would explain why their fears are direct- 
ed at ghosts and animals. Bauer's emphasis on cognitive development makes sense. For example, the visual cliff phenomenon (i.e., fear of heights) that typically occurs in young babies between 4 and 9 months has long been interpreted as a prototype of a genetically based fear. Yet, experiments show that this phenomenon critically depends on locomotor development in infants (Bertenthal \& Campos, 1984). A (social) developmental interpretation of the different onset ages of fears and phobias is also presented by Öhman (1987). Öhman points out that animal fears typically occur during a developmental phase in which young children become more independent from their parents. From an evolutionary perspective, it may be assumed that during this phase, children are vulnerable to predators. The sensitivity of young children to phobogenic animal stimuli would, therefore, have survival value.

Thirdly, Although the majority of childhood fears disappear spontaneously, there are also indications that in a subgroup of children, the specific fears do not wane with the passage of time (e.g., Ollendick, 1979). Thus, the critical question to be asked is why in some cases, specific fears appear to persist from childhood into adulthood. Part of the answer probably lies in the heritability factor associated with fear. For example, Stevenson et al. (1992) found suggestive evidence that the influence of this heritability increases with age:

as children move through adolescence this would then lead to avoidance behaviour which would reinforce the fearfulness of these individuals genetically prone to fearfulness. The net effect will be an increasing significance of genetic influences over individual differences with age. (p. 984)

Findings such as those of Stevenson et al. suggest that genetically-based personality traits affect the development of childhood fears. A study by Biederman et al. (1990) underlines this suggestion. These authors examined behavioral inhibition (i.e., the tendency to react with arousal and withdrawal to unfamiliar settings) in young children. Behavioral inhibition reflects a temperamental characteristic that is closely linked to the presumably inherited trait of introversion. Bierderman et al. found that behavioral inhibition at 21 months predicts the number of phobic fears at age 8 .

Several authors have argued that the stimuli that elicit developmental fears (e.g., fear of strangers, fear of heights, fear of separation, etc.) represent "prepotent" cues (Menzies \& Clarke, 1995). In their view, these cues once posed a challenge to the survival of prehistoric man and "innate" fear reactions to them would have increased fitness. Therefore, the developmental fears are spontaneous in the sense that they are not dependent on aversive associative learning (e.g., conditioning). Supporters of this nonassociative view further claim that specific phobias seen in adult patients echo these early, innate fears. But if this is the case, one might ask why all adults do not suffer from specific phobias. Menzies and Clarke (1995) propose that poor habituators may remain fearful of innate fear cues. In these individuals, developmental fears take a chronic course. Alternatively, nonspecific stressors (e.g., interpersonal conflicts) may promote dishabituation and the reinstatement of developmental fears (see, for a similar line of reasoning, Jacobs \& Nadel, 1985). In either case, specific phobias would reflect developmental fears which, in turn, would derive from innate fear reactions to prepotent stimuli. Although this analysis is consistent with the finding that a substantial proportion of patients with specific phobias report that they have always been afraid (Menzies \& Clarke, 1993a, 1993b, 1994, 1995), it is flawed on several counts. To begin with, its claim that developmental fears and specific phobias involve innate fear stimuli assumes that researchers can reconstruct the challenges of the Pleistocene 
savannah. This assumption is problematic. Although it may be plausible to assume that fear of heights or fear of strangers are relevant to fitness, an adaptive argument for, say, fear of spiders is less persuasive. Only a tiny percentage (i.e., $0.1 \%$ ) of the 35,000 spider varieties are dangerous (Renner, 1990) and pretechnological man must have had more urgent problems than dealing with spiders. Furthermore, the nonassociative account leaves unexplained why not all people suffer from specific phobias. Why, exactly, do some individuals habituate rapidly and others poorly to prepotent fear stimuli? The nonassociative account has no ready answer to this question. Similarly, the idea that nonspecific stress may provoke a return of developmental fears leads to an overprediction of the prevalence of phobias in adults. Most individuals will now and then experience aversive life events, but only a minority of them actually develop a specific fear (see also McNally, 1989).

The nonassociative account is also difficult to reconcile with the results from genetic and epidemiological research. In their large-scale study on twins, Kendler and colleagues (1992) found that specific phobias are the joint product of a modest common genetic factor and learning experiences that are highly specific to these phobias. Research suggest that apart from this genetic factor, three types of learning might contribute to the persistence of childhood fears, namely classical conditioning, modelling, and negative information transmission.

\section{PATHWAYS TO SPECIFIC PHOBIA}

\section{Classical Conditioning}

Ever since Watson and Rayner's "Little Albert" study (1920), researchers have sought to explain the etiology of specific phobias in terms of aversive classical conditioning. Typically, this has been taken to mean that fear of a neutral stimulus (e.g., a dog) can be traced back to the cooccurrence of this stimulus with a highly aversive incident (e.g., being bitten by a dog). The basic phenomenon of aversive classical conditioning (i.e., fear can be conditioned to a CS [conditioned stimulus] by pairing that CS with an aversive UCS [unconditioned stimulus]) has been documented many times. For example, in a study of Campbell, Sanderson, and Laverty (1964), subjects listened to a tone (CS) that was followed by an injection of scoline. This injection produced a temporary respiratory paralysis (UCS) and, consequently, intense fear (UCR). Even weeks after this single conditioning trial, subjects reacted with strong autonomic responses (CR) to isolated presentations of the tone (i.e., the tone was not followed by paralysis).

Although laboratory findings such as these illustrate that conditioning processes can, in principle, produce phobia-like fears, they do not prove that in everyday life, classical conditioning is the cause of phobias. However, there is evidence to support the notion that classical conditioning processes do operate outside the laboratory chambers. For example, Kuch, Cox, Evans, and Shulman (1994) reported that of 55 survivors of road vehicle accidents (UCS), $21(38 \%)$ developed a phobia related to driving a car (CS). Likewise, choking phobia (classified in DSM-IV terms as a specific phobia "other type") is nearly always the result of a traumatic incident, for example, in which the patient chokes on a fishbone (Greenberg, Stern, \& Weilburg, 1988). Moore, Brodsgaard, and Birn (1991) concluded that the largest cause of dental phobia is a traumatic dental experience.

The classical conditioning model of phobias explains why persons react with subjective and physiological fear when they are exposed to a phobic CS. Yet, it does not account for the persistent avoidance behavior that phobics display. The influential two-stage theory of Mowrer (1960) attempts to incorporate this point. Briefly, Mowrer 
assumes that the development of phobias involves two stages. During the first stage, a pairing of a neutral CS and an aversive UCS results in a conditioned fear response to the CS. During the second stage, the person learns that fear responses to the CS can be reduced by avoiding the CS. The reduction in fear levels that follows avoidance behavior reinforces this behavior and in time, avoidance becomes an integral part of the phobia. Again, research shows that the scenario depicted by the two-stage theory works in the laboratory. Thus, when subjects are confronted with pairings of light (CS) and shock (UCS) and then are given the opportunity to react with an escape response every time the CS appears, persistent avoidance responding occurs (Malloy \& Levis, 1988).

In the 1970s, several authors argued that the classical conditioning model of phobias and its extension, Mowrer's two-stage theory, suffer from a number of serious shortcomings (see, for initial overviews, Rachman, 1976, 1977; Eysenck, 1979). To begin with, the conditioning approach fails to explain why specific fears are nonrandomly distributed. Indeed, from a conditioning point of view, one would expect that each object can become a phobic stimulus (CS), provided that it is followed by an aversive event (UCS). As mentioned, this is not the case: Fear of snakes occurs more often than fear of, say, electricity although there is no obvious reason to suspect that snakes are more frequently associated with UCSs than electricity (Seligman, 1971).

Secondly, contrary to all predictions that flow from the classical conditioning model, people do not always acquire phobic fears as a result of aversive confrontation (Saigh, 1984). There is abundant evidence to show that aversive experiences (UCSs) with spiders, dentists, or dogs per se do not give rise to spider phobia, dental phobia, or dog phobia, respectively (diNardo, Guzy, \& Bak, 1988; Lautch, 1971; Merckelbach, Arrindell, Arntz, \& de Jong, 1992). Obviously, then, trauma (UCS) without subsequent phobia does occur.

Thirdly, not all specific phobias can be traced back to a confrontation with a traumatic or aversive event (UCS). In other words, some people develop a fear response to a CS, although this CS has never been paired with a UCS (Wolpe, Lande, McNally, \& Schotte, 1985; Menzies \& Clarke, 1995). Thus, phobia without preceding trauma (UCS) is possible.

Fourthly, the avoidance behavior implicated in Mowrer's extension of the classical conditioning model is active avoidance of the UCS, whereas the behavior exhibited by phobics is passive avoidance of the CS (Seligman, 1971; Mineka, 1985).

Other shortcomings of the traditional conditioning model are extensively dis cussed in review papers by Davey (1992a), Menzies and Clarke (1995), Mineka (1985), and Rachman (1990a, 1990b, 1991). The failures of the traditional conditioning approach to phobias paved the way for two types of revision. The first one attempts to revise the classical conditioning model along biological lines. The second type of revision is more cognitively oriented.

\section{Preparedness and Neurohormones}

The preparedness hypothesis (Seligman, 1971) is a good example of a biologically oriented revision of the classical conditioning model. According to this hypothesis, aversive conditioning interacts with evolutionary processes to produce phobic fear. Consequently, aversive events (UCSs) in the context of evolutionary recent objects (e.g., electricity) would not produce a phobic fear, whereas such events in the context of evolutionary relevant items (e.g., snakes) would do so. Several human and animal studies have tested this idea under laboratory conditions and found evidence to support the 
preparedness position. Öhman and associates conditioned autonomic reactions of normal subjects to evolutionary relevant (e.g., slides of spiders) or evolutionary neutral (e.g., slides of flowers) stimuli by pairing these stimuli with aversive electric shock UCSs. In more than a dozen studies, these researchers found that once acquired, conditioned responses to evolutionary relevant cues are slower to extinguish than conditioned responses to evolutionary neutral cues (see, for reviews, Öhman, 1986, 1993). Thus, these experiments seem to support the central tenet of the preparedness hypothesis, namely that subjects readily acquire robust associations between evolutionary relevant cues and aversive outcomes.

A similar conclusion can be drawn from studies examining the acquisition of fears in rhesus monkeys. Mineka and coworkers (Mineka, 1987; Cook \& Mineka, 1989; Mineka \& Cook, 1993) exposed laboratory-reared monkeys ("observers") with no prior fear of snakes to videotapes of wild-reared ("models") reacting fearfully in the presence of a snake or a flower. Using editing techniques, Mineka and associates were able to design the videotapes in such a way that model monkeys displayed identical fear behaviors toward evolutionary relevant (i.e., snakes) and evolutionary neutral (i.e., flowers) stimuli. With this paradigm, these researchers demonstrated that observer monkeys acquire an extremely persistent fear of snakes after they have watched models reacting fearfully to snakes. In contrast, observer monkeys failed to acquire a fear of flowers after they had seen models exhibiting identical fears of flowers.

In spite of the supportive evidence, the preparedness hypothesis is in dispute (Davey, 1995; Delprato, 1980; McNally, 1987). Some authors (e.g., McNally, 1995a) have criticized the "adaptationist" assumption that underlies the preparedness hypothesis. They argue that it is difficult to determine the evolutionary relevance of various stimuli and that Darwinian arguments run the risk of being "adaptive stories" that heavily rely on plausibility. Other critics (e.g., Merckelbach \& de Jong, 1996) have emphasized that several studies have failed to replicate the basic findings of Öhman and colleagues. For example, McNally and Foa (1986), Packer, Clark, Bond, and Siddle (1991), and Kirsch and Boucsein (1994) were unable to show that responses conditioned to evolutionary relevant cues are more resistant to extinction than are responses conditioned to evolutionary neutral cues. Thus, it is not clear what parameters are important for the resistance to extinction effect to be observed. Still other critics (e.g., Davey, 1995) have pointed out that the results of Öhman and coworkers and those of Mineka and associates are open to alternative interpretations. For example, the resistance to extinction effect that occurs with evolutionary relevant cues might be the product of preexperimental expectancies that are rooted in culture rather than genes (see, for an extensive discussion, Davey, 1995).

Another attempt to revise the conditioning model along biological lines proposes that the phobogenic effects of CS-UCS pairings interact with the neurohormonal state of the organism (e.g., Kelley, 1987). In Kelley's (1987, p. 403) words: "neuroses = conditioning $\times$ neurohormones." More specifically, Kelley argues that high levels of adrenocorticotrope hormone (ACTH) and vasopressin enhances the effects of CSUCS pairings, whereas high levels of endogenous opioids (i.e., endorphins) attenuate these effects. Thus, some subjects would be more vulnerable to CS-UCS pairings because they habitually have heightened levels of ACTH and vasopressin and/or lowered endorphin levels. There is some indirect evidence to support this line of reasoning. For example, phobic fear is accompanied by either elevated or reduced levels of certain (neuro)hormones (Cameron \& Nesse, 1988). Furthermore, primate studies strongly suggest that ACTH levels might partly account for individual differences in fear behavior (Kalin, 1993). Similarly, developmental studies by Kagan and associ- 
ates have found that elevated basal levels of the ACTH-induced hormone cortisol is predictive of children's fear responses in threatening situations (Kagan, 1983). However, thus far, Kelley's proposal has not been put to a direct test in studies with adult phobics. All that one can conclude from the evidence at hand is that lowering endorphin levels by applying naltrexone (i.e., an opioid antagonist) intensifies fear in subjects who are already phobic (e.g., Arntz, Merckelbach, \& de Jong, 1993; Merluzzi, Taylor, Boltwood, \& Götestam, 1991). However, there are no indications that neurohormones such as endorphins are directly involved in the etiology of specific phobias. In fact, the proposition that lowered endorphin levels enhance the effects of fear conditioning received no support in a laboratory study by Merckelbach, Arntz, de Jong, and Schouten (1993). Obviously, it remains to be seen to what extent neurohormones such as ACTH and vasopressin modulate the development of specific phobias.

A related line of research has examined the role of sex hormones in the acquisition of phobic fear. For example, Cameron and Nesse (1988) state that "sex hormone fluctuations in women during the menstrual cycle may be related to changes in anxiety levels" (p. 291). Villa and Beech (1977) as well as Van der Molen, Merckelbach, and van den Hout (1988) found that premenstrual women show an increased susceptibility to fear conditioning. Yet, a major problem with these studies is the absence of a control group of men. Accordingly, on the basis of these studies it is impossible to determine whether premenstrual women are more or whether intermenstrual women are less susceptible to fear conditioning than are men. The interpretative problems are further aggravated by a study of Hedlund and Chambless (1987), who included a control group of men, but could not replicate the superior conditioning effects in premenstrual women. Thus, although it is tempting to relate the uneven men/women ratio of some specific phobia types to fluctuations in sex hormones, the evidence for such an account is still meagre.

\section{The Neoconditioning Perspective}

The second type of revision of the classical conditioning model is more cognitively oriented. Heavily inspired by studies on conditioning processes in animals (e.g., Rescorla, 1971), advocates of this revision point out that conditioning is not the blind, reflexive process that it is often assumed to be (e.g., Bouton \& Swartzentruber, 1991; Davey, 1992a; van den Hout \& Merckelbach, 1991). They point uut that in human fear conditioning, S-S learning rather than S-R learning is the typical scenario. That is to say, fear conditioning is usually a cognitive process during which one learns that the CS predicts an aversive UCS (see Reiss, 1980; van den Hout \& Merckelbach, 1991, for a more detailed discussion of this topic). This conceptualization departs radically from the older view that during aversive conditioning, fear responses become reflexively tied to the CS (i.e., S-R learning).

The S-S approach, or in Rachman's (1991) words "the neoconditioning perspective," has a number of interesting ramifications and is able to avoid some of the inadequacies of the traditional conditioning model. They are reviewed in depth by Mineka (1985), Rachman (1991), and Davey (1992a). Their detailed comments will not be repeated here. Instead, we limit our review to two interesting aspects of the neoconditioning perspective, aspects that have been directly linked to the etiology of specific phobias. First, the neoconditioning model emphasizes a phenomenon known as "latent inhibition." Suppose a subject has extensive experience with a CS (e.g., light) that is not followed by an aversive UCS. What happens when later this subject is exposed to a new situation in which the CS is suddenly accompanied by a painful 
UCS (e.g., electric shock)? Will the CS now elicit a conditioned fear response? Laboratory experiments show that it is difficult to condition fear responses to a familiar CS that was formerly never associated with an aversive UCS (Booth, Siddle, \& Bond, 1989). Recall that during conditioning, subjects learn that the CS is a predictor of a UCS. If the subject has repeatedly experienced that the CS predicts nothing and is innocuous, an incidental cooccurrence of the CS and an aversive UCS may not be powerful enough to make the subject "believe" that the CS has changed into a predictor of the UCS. In other words, prior nonaversive experiences with the CS inhibit fear conditioning. The phenomenon of latent inhibition may explain why traumatic experiences (i.e., UCSs) fail to result in subsequent phobias. For instance, Doogan and Thomas (1992) found that traumatic encounters with dogs are reported by both subjects with fear of dogs and subjects without fear of dogs. However, the latter group reported more previous nonaversive contact with dogs. This suggests that in the nonfearful group, latent inhibition helped to minimize the effects of fear conditioning. A similar result was reported by De Jongh, Muris, Ter Horst, and Duyx (1995), who found evidence to suggest that latent inhibition plays a role in the etiology of dental fear (see also Davey, 1989a).

A second concept that might be helpful in revising the traditional conditioning model is UCS inflation (Davey, 1989b). Briefly, UCS inflation is a phenomenon that was first described in animal conditioning research (Rescorla, 1971). Basically, it refers to a situation in which subjects are exposed to pairings of a CS and a mild UCS. As a result of this, subjects learn that CS and UCS are related. However, given the low intensity of the UCS, this SS association leads to a weak conditioned fear response. Now the following may happen. If subjects during a next phase learn that the UCS is more aversive than previous experience suggested, this postconditioning information will lead to an inflation of the UCS value as it is stored in memory. Consequently, the conditioned fear response will grow in strength. A clinical example taken from White and Davey (1989) illustrates how this scenario can account for cases in which conditioned fear emerges without pertinent trauma:

An individual may witness an unknown person die of a heart attack on a bus or a train. On future occasions, riding on public transport may evoke memories of this incident but no anxiety. ... Subsequently, however, that individual may be present when a close friend or relative dies of a heart attack, thus inflating the aversive properties of heart attacks. This may then give rise to acute anxiety when riding on public transport. In this particular scenario, public transport has never been directly associated with anxietyeliciting trauma, but the public transport phobia results from a prior learned association between public transport and heart attacks, and subsequent independent inflation of heart attacks as aversive events. (p. 165)

Several case histories of phobia can be interpreted in terms of UCS inflation (Davey, de Jong, \& Tallis, 1993). The UCS inflation concept suggests an elegant account of phobias without trauma. Yet, laboratory experiments with human subjects show that it is hard to produce robust fear conditioning through UCS inflation (de Jong, Merckelbach, Koertshuis, \& Muris, 1994; de Jong, Muris, \& Merckelbach, 1996). Thus, there are theoretical and clinical arguments to believe that UCS inflation is a real phenomenon, but the specific conditions under which it becomes manifest are ill understood.

To recapitulate, neoconditioning concepts such as latent inhibition and UCS inflation can deal with some inadequacies of the traditional conditioning approach. More specifically, latent inhibition can explain why UCS trauma does not always lead to pho- 
bia, while UCS inflation can explain why phobia without pertinent UCS trauma is possible. Meanwhile, it should be acknowledged that the neoconditioning view is, as Rachman (1991) says, "still too liberal. It lacks limits and there is little that it disallows" (p. 169). Thus, a further sophistication of the model is required and findings from the animal literature might be very helpful to accomplish this (see, e.g., Mineka, 1985; Bouton \& Swartzentruber, 1991).

\section{Indirect Pathways to Phobia: Modelling and Negative Information}

The classical conditioning pathway to fear assumes that subjects have direct experience with a CS and a UCS. This is true for straightforward conditioning in which a CS is paired with a traumatic UCS, as well as for subtle conditioning scenarios such as latent inhibition and UCS inflation. However, there are cases in which subjects develop a specific phobia although they have no history of direct experience with the CS (i.e., phobic object) and/or UCS (Rachman, 1977, 1990b, 1991). In these cases, indirect pathways of fear acquisition might play a pivotal role. Rachman $(1977,1990 \mathrm{~b}$, 1991) provides a detailed description of two indirect pathways that are important in this context: modelling (i.e., vicarious transmission of fear) and negative information.

The modelling pathway assumes that phobic fears can be acquired by watching others reacting fearfully to a stimulus. This assumption is supported by both animal and human laboratory studies. As mentioned earlier, Cook and Mineka (1989) found that rhesus monkeys can acquire a fear of snakes through watching video-tapes of model monkeys reacting fearfully to toy snakes. Likewise, Hygge and Ôhman (1978) demonstrated that subjects respond with sympathetic activation to pictures of, for example, snakes when they have previously observed others being frightened by these pictures. Other examples of the vicarious acquisition of autonomic fear responses are presented by Green and Osborne (1985).

In turning to negative information, it seems obvious that verbal information about certain stimuli that is provided by significant others (e.g., parents), books, or television may give rise to fear of these stimuli. If this was not the case, prevention programs concerned with smoking or AIDS would make no sense. While there is a paucity of experimental studies on the fear-evoking characteristics of negative information, social psychological studies show that subjects assign more value to negative than to positive information. There might be good evolutionary reasons for this asymmetry (e.g., Pratto \& John, 1991). Assuming that modelling and negative information transmission are closely tied to familial interactions, one would expect that there is a familial aggregation of specific phobias. A study of Fyer and colleagues (1990) shows this to be the case. These researchers found, for example, that $31 \%$ of the relatives of specific phobia probands as compared to $11 \%$ of control relatives had a lifetime diagnosis of specific phobia. Although this study did not distinguish between different etiological mechanisms (e.g., genetic inheritance, modelling, etc.), its results are consistent with the idea that modelling and negative information do operate in families. Likewise, a recent study by Muris, Steerneman, Merckelbach, and Meesters (1996) demonstrated that fears reported by children are a function of the extent to which mothers express their own fears in the presence of their children. This association was independent of the influence of trait anxiety levels in mothers.

\section{The Role of Disgust}

The classical conditioning route consists of the acquisition of danger expectancies. While this is also true for modelling and information processing, there is another type 
of evaluation that might be transmitted through these pathways. Of special interest in this context is the role of disgust and disgust sensitivity. In a series of studies, Davey and coworkers (e.g., Davey, 1994a; Matchett \& Davey, 1991) demonstrated that normal subjects tend to evaluate small animals such as spiders, snakes, and rats as disgust-evoking rather than dangerous. These researchers also found that fear of, for example, spiders covaries with fear of small animals that are usually considered to evoke disgust (e.g., snake, bat, cockroach, etc.; Ware, Jain, Burgess, \& Davey, 1994). Similarly, Bennett-Levy and Marteau (1984) showed that there is a positive correlation between fear of these small animals and the extent to which they are perceived as ugly and slimy. Accordingly, one could speculate that when such evaluations are transmitted through modelling and negative information, people with a high disgust sensitivity come to fear these small animals. Disgust sensitivity is a trait that can be measured with a questionnaire that focuses on food rejection (e.g., Matchett \& Davey, 1991). Interestingly, in normal subjects, there is a positive correlation between disgust sensitivity scores and fear of small animals (Davey, 1994a; Davey, Forster, \& Mayhew, 1993; Matchett \& Davey, 1991). Furthermore, spider phobic subjects have a higher disgust sensitivity than normal control subjects (Merckelbach, de Jong, Arntz, \& Schouten, 1993). A study by Mulkens, de Jong, and Merckelbach (in press) adds to the evidence that disgust-evoking characteristics heavily contribute to the phobogenic nature of spiders. Their data not only show that an intense fear of spiders is related to a heightened disgust sensitivity, but also that spiders share the striking feature of any disgusting substance, namely that they can "contaminate" a perfectly good food item by brief contact.

As most studies on disgust and phobia relied on a correlational approach, they do not rule out the possibility that fear enhances disgust and/or disgust sensitivity rather than vice versa. However, an experiment of Webb and Davey (1992) clearly indicates that fear is causally affected by disgust. In that study, it was found that prior exposure to revulsive material (i.e., video scenes of a medical operation) leads to an increase in fear of spiders, snakes, etc. Note that the studies on disgust and disgust sensitivity in animal phobias have come up with results that are difficult to reconcile with a preparedness account of these phobias. The preparedness view capitalizes on the alleged dangerousness of animals such as spiders, snakes, and the like. Yet, the work of Davey and associates show that fear of these animals is related to disgust rather than perceived dangerousness.

The role of disgust and disgust sensitivity is not restricted to the domain of small animal fears. For example, Page (1994) suggested that disgust sensitivity is a vulnerability factor for the fainting response seen in blood-injection-injury phobia. Germane to this issue is the study of Matchett and Davey (1991) in which a positive correlation was found between disgust sensitivity and self-reported blood-injection-injury fear.

\section{Retrospective Clinical Studies}

Several studies have sought to assess the extent the aforementioned pathways to fear contribute to the etiology of specific phobia (e.g., Öst, 1987a; Merckelbach et al., 1992; Kleinknecht, 1994). Most of these studies have employed the Phobic Origin Questionnaire (POQ; Öst \& Hugdahl, 1981), a self-report instrument that asks phobic patients to what degree their phobia developed along a direct (i.e., conditioning) and/or an indirect (i.e., modelling; negative information) route. A potential problem in these studies is, of course, that phobics are invited to provide a retrospective judgement as to the cause of their complaints. With this type of research strategy, several biases (e.g., memory distortions) may occur (see, for critical reviews, Kirkby, Menzies, Daniels, \& Smith, 1995; Menzies \& Clarke, 1994; Whiters \& Deane, 1995). On the 
other hand, Brewin, Andrews, and Gotlib (1993) have summarized evidence to suggest that, in general, claims about the unreliability of retrospective reports are exaggerated. More relevant to the present context is a recent study by Kheriaty, Kleinknecht, and Hyman (in press). In that study, phobics' retrospective accounts of onset experiences were sent to their parents for verification. The authors found that a majority of the onset events reported by phobics could be confirmed by their parents. Although the authors notice that a structured interview may elicit more reliable reporting of phobia onset events than the POQ their results provide some support for the validity of phobics' retrospective account.

Several interesting findings have emerged from retrospective studies on phobia origin (see, for reviews, Kleinknecht, 1994; Ôst, 1987a, 1987b, 1991). First, while each of the three pathways is represented in the various subtypes of specific phobia, direct conditioning-like experiences seem to be the predominant mode in phobia acquisition. However, there are large differences in the distribution of the three routes between the various subtypes of phobia. For example, animal phobics and bloodinjection-injury phobics more often ascribe their fears to modelling and negative information than do claustrophobics. In contrast, the conditioning pathway is more pronounced in claustrophobia than in animal, blood-injection-injury or height phobia (Öst, 1987a; Menzies \& Clarke, 1993). Interestingly, Öst (1987a) found that modelling and negative information are associated with an early onset age.

Second, several studies (Merckelbach, Arntz, \& de Jong, 1991; Milgrom, Mancl, King, \& Weinstein, 1995; Ollendick \& King, 1991) have found that fearful subjects often report more than one pathway. There are even indications that subjects with "mixed" pathways (e.g., conditioning and modelling) have higher levels of fear. Third, the three pathways to fear are also reported by children (Ollendick \& King, 1991; see also Doogan \& Thomas, 1992). This suggests that these etiological mechanisms do, indeed, operate during the early developmental phases.

An interesting speculation about the interrelationship between the three pathways to fear, the three components of fear, and treatment interventions was put forward by Rachman (1977; de Silva \& Rachman, 1981). Rachman proposed that there might be a systematic connection between etiology of phobia, symptom profiles of phobia, and treatment of phobia. According to Rachman, phobias based on a direct conditioning pathway would be dominated by behavioral and physiological symptoms, whereas indirectly acquired phobias would be characterized by cognitive symptoms. Consequently, the first class of phobias would profit more from exposure based interventions, whereas the second class of phobias would benefit more from cognitive interventions (see also Wolpe, 1981). So far, attempts to evaluate the empirical merits of Rachman's suggestions have largely come up with disappointing results (cf. Öst, 1987b). As the earlier discussion indicated, phobic patients often attributc their complaints to two or three pathways. Moreover, several studies have failed to find a significant association between pathways to fear and loadings on the three symptoms systems (Öst, 1991; Withers \& Deane, 1995). However, Eifert and Wilson (1991) rightly remarked that "the matching of profiles and treatments may have been too broad and crude in some previous study" (p. 289). Consequently, Rachman's suggestion warrants further investigations with more precise matching methods.

\section{COGNITIVE BIASES}

Specific phobias are acquired through direct and/or indirect learning pathways. But how are phobic fears maintained once they are acquired? A modern version of 
Mowrer's two-stage model (Malloy \& Levis, 1988) suggests that avoidance behavior is responsible for the conservation of phobic fear: Avoidance would minimize direct and prolonged contact with the phobic object and, hence, phobic subjects would not have the opportunity to learn that the CS is a neutral object and does not predict danger.

Although it is plausible that avoidance behavior plays a role in the conservation of fear (cf. Rachman, Craske, Tallman, \& Solyon, 1986), other psychological processes may do so, too. These mechanisms are cognitive in nature and have been the object of extensive research in the past years (for reviews, see Dalgleish \& Watts, 1990; McNally, 1995b; Mineka \& Sutton, 1992). Most researchers agree that pathological anxiety (e.g., specific phobia) is not characterized by a general cognitive dysfunction. In other words, pathological anxiety is not associated with overall deficits in memory, attention, motor function, and the like. Instead, cognitive dysfunctions in specific phobias appear to be restricted to certain information processes and to certain semantic domains. First, phobic subjects show evidence of dysfunctions in attentional and inferential (i.e., judgmental) processes. In contrast, depressive patients exhibit dysfunctions in memory rather than attention (Mineka \& Sutton, 1992). Second, the attentional and judgmental biases that accompany phobias are tied to specific stimuli. That is to say, these biases become apparent if and only if subjects are confronted with fear-relevant stimuli (e.g., the word spider in case of a spider phobic subject).

\section{Attentional Bias}

Attentional bias refers to the phenomenon of hyperattention to threatening material. This hyperattention occurs even with verbal material that is not relevant to the primary task in which the subject is involved. One frequently employed technique for demonstrating attentional bias is the modified Stroop color task, although various authors have questioned its adequacy as an index of attention (for reviews, see M. W. Eysenck, 1992; MacLeod, 1991). The modified Stroop task requires subjects to name the color of a word while ignoring the meaning of that word. A consistent finding in Stroop studies with anxious patients is that the their color naming of threatening words is slower than that of neutral words (Dalgleish \& Watts, 1990). For example, spider phobics display retarded color naming latencies when they are confronted with spider related words (e.g, spider, creepy), but not when they have to color name neutral words (e.g., car) (Lavy, van den Hout, \& Arntz, 1993). A plausible interpretation of this effect is that spider phobics automatically direct their attention to the content of the threatening words and this interferes with their main task (i.e., color naming). Studies employing other paradigms (e.g., dichotic listening: Burgess, Jones, Robertson, Radcliffe, \& Emerson, 1981; complex reaction time tasks: Streblow, Hoffman \& Kasielke, 1985) have demonstrated similar bias effects in specific phobia and this converging evidence underlines the attentional bias interpretation. The phenomenon of an automatic attentional bias accords well with Öhman's (1993) hypothesis that a quick and dirty subcortical route is responsible for the transmission of phobic information. It is also consistent with Fredrikson et al.'s (1995) speculation that the increased secondary visual cortex activation during phobic provocation reflects vigilance.

Specific fears are accompanied by perceptual distortions as well. For example, Rachman and Cuk (1992) found that spider fearful subjects are more inclined to perceive a spider in a bowl as jumping towards them than do nonfearful subjects (see also Riskind, Moore, \& Bowley, 1995). These perceptual distortions disappear when fear declines. It is tempting to relate perceptual distortions to the attentional bias phenomenon. It is well-known that confrontation with emotional stimuli leads to an increase in 
arousal which, in its turn, can cause attentional narrowing (Christianson, 1992). Attentional narrowing implies hyperattention to central detail information and hypoattention to peripheral details. One could speculate that such an attentional asymmetry underlies both attentional bias and perceptual distortions (Rachman \& Cuk, 1992).

As to the clinical consequence of attentional bias, it seems likely that an increased focus on danger and threat stimuli perpetuates phobic fear. That is, attentional bias implicates an increased encoding of threatening material and this, in turn, will elevate fear levels (Mineka \& Sutton, 1992). To the degree that the increased encoding is followed by an avoidance of full stimulus elaboration (Watts, Trezise, \& Sharrock, 1986), the attentional bias will hinder the extinction of fear. Germane to this issue are the findings of MacLeod and Hagan (1992). These authors found that an attentional bias towards threat-related material is a good predictor of emotional distress elicited by a subsequent stressful life event. However, further studies are needed to establish that attentional bias is associated with symptom severity and relapse after treatment in specific phobia (Logan \& Goetsch, 1993).

\section{Judgmental Bias}

There are two types of judgmental bias that may play a role in the maintenance of specific phobia. The first type is the covariation bias, that is, the tendency to overestimate the association between phobic stimuli and aversive outcomes (Tomarken, Mineka, \& Cook, 1989; Tomarken, Sutton, \& Mincka, 1995). The cxperimental demonstration of covariation bias in phobias is straightforward. Phobic and normal subjects are shown a series of slides consisting of fear-relevant pictures (e.g., spiders) and fear-irrelevant pictures (e.g., flowers). Slide offset is followed by one of three outcomes, namely an aversive shock, a tone, or nothing. Fear-relevant and fear-irrelevant pictures are equally often followed by each of the outcomes. After the series of slides, subjects are asked to estimate the contingencies between slides and outcomes ("given that you saw a spider slide, on what percentage of those trials was the spider followed by a shock?"). Under these experimental conditions, phobic subjects systematically overestimate the contingency between phobic stimuli and aversive outcomes. Again, there is evidence to suggest that the covariation bias is reduced in successfully treated spider phobics (de Jong, Merckelbach, Arntz, \& Nijman, 1992; de Jong, Merckelbach, \& Arntz, 1995). Furthermore, de Jong, van den Hout, and Merckelbach (1995) found that there is a strong and positive correlation between residual covariation bias in treated spider phobics and relapse. That is, the stronger the (post-treatment) overestimation of the contingency between spider picture and aversive shock, the higher the spider fear at 2-year follow-up. The implication of this covariation bias is clear: Phobics have a tendency to attribute aversive experiences to the phobic object and this, in turn, will sustain phobic fear.

A second judgmental bias that may occur in specific phobias is a style of "emotional reasoning" (e.g, Beck \& Emery, 1985) known as ex consequentia inference. Like other people, phobics rightfully assume that dangerous situations elicit anxiety. However, unlike many nonphobic subjects, spider phobics seem to believe that anxiety symptoms imply the presence of danger (dangerous spiders, etc.; Arntz et al., 1995). The ex consequentia inference probably serves to legitimate the phobic fear and, thus, may maintain the phobia. However, more studies are needed to firmly establish the role of this reasoning style in the maintenance of fear.

\section{The Origins of Cognitive Biases}

Cognitive biases are not limited to specific phobias. That is to say, they are also evident in other anxiety disorders (e.g., social phobia, panic disorder, etc.; Logan \& Goetsch, 
1993). Moreover, cognitive biases apparently occur automatically in that they are not under voluntary control (McNally, 1995b). It is interesting to speculate about the origins of cognitive biases. One hypothesis that deserves consideration is that cognitive biases emerge from a right hemisphere mode of information processing (Merckelbach, Muris, \& de Jong, 1990). Most researchers agree that the left hemisphere sustains an analytic and serial approach, while the right hemisphere mediates an holistic and imaginal approach. Tucker and Newman (1981) have argued that the left hemisphere processing mode is very effective in controlling emotional reactions, whereas the right hemisphere mode leads to an intensification of affect. Perhaps, conditions such as specific phobias prime the right hemisphere processing mode which, in turn, would give rise to hyperattention to threat and overestimation of aversive outcome. Although this suggestion must be considered speculative, there is some experimental work that supports this causal relationship (de Jong, Merckelbach, \& Nijman, 1995; see also Heller, Etienne, \& Miller, 1995).

Apart from neuropsychology, developmental research might provide fresh ideas about the origins of cognitive biases. For example, using the modified Stroop task, Kindt, Bierman, and Brosschot (1996) examined color naming latencies in high spider-fearful and control children aged 8-12 years. These researchers demonstrated that attentional bias was not restricted to the high fearful subgroup, but emerged in the control group as well. Furthermore, in the control group, a negative association was found between age and attentional bias. That is, the older the children, the less evident their attentional bias for spider-related words. Within the high fearful group, such an age effect was not present. These findings raise the possibility that attentional bias to threat is common in children, but that it diminishes as time goes by. Kindt et al. speculate that nonfearful children learn to inhibit selective processing of threat cues. Accordingly, the development of childhood fears into adult phobias may be marked by a failed inhibition of selective attention.

According to M. W. Eysenck (1992), attentional bias is closely linked to fundamental personality dimensions such as trait anxiety and neuroticism. In accordance with this, some studies have reported elevated levels of trait anxiety in specific phobias (e.g., Watson, Clark, \& Carey, 1988). Yet, other studies were unable to find a connection between trait anxiety and specific phobias (e.g., spider phobia; Davey, 1992b). Possibly, the precise relationship between personality dimensions and specific phobia depends on the type of phobia that one is studying.

\section{CONCLUDING REMARKS}

Specific phobias have been well researched in the past decades. As a result, we now have a rather comprehensive picture of the important elements that constitute this disorder. To recapitulate the most important points, specific phobias form a heterogeneous class of disorders that are characterized by etiologic diversity (Himle et al., 1991). The most radical difference is to be found between animal phobias and claustrophobia. Compared to animal phobias, claustrophobia is accompanied by a more elaborated set of cognitions, a later age of onset, and a more pronounced role of conditioning onset events (Öst, 1987a). In small animal phobias, but also blood-injection-injury phobia, the predominant pathways to fear are modelling and negative information transmission. Furthermore, it is likely that disgust and disgust sensitivity contribute to the development of these specific phobia types (Page, 1994). Further evidence for the radical difference between claustrophobia and animal phobias comes from treatment studies. In claustrophobia, but not in animal phobias, treat- 
ment effects might be enhanced by combining therapeutic exposure with cognitive interventions (Craske et al., 1995).

By and large, specific fears are common in childhood and there are reasons to believe that cognitive and social development is closely linked to the content of these fears. These fears represent transitory phenomena in most children (Marks, 1987). However, in a small subgroup of children and adolescents, the specific fears become chronic due to conditioning, modelling, and/or negative information. Possibly, a general genetic contribution to neuroticism or a more specific heritability factor also plays a role in this process (Stevenson et al., 1992). Once, a specific phobia exists, it is maintained by cognitive biases such as attentional bias and covariation bias. Consequently, in most cases, the natural course of specific phobias is chronic (Wittchen, 1988).

Several questions remain. For example, the origins of the skewed sex distribution of most specific phobias are not well understood. Possibly sex hormones interact with conditioning processes to produce such skewed distribution. However, more research is needed to evaluate this hypothesis. In more general terms, it might be worthwhile to subject Kelley's hypothesis that "neurosis $=$ conditioning $\times$ neurohormones" to systematic research. Another point that is still elusive, is the nonrandom distribution of specific fears. Why is it that phobic fears are more often directed at, say, snakes than at, for example, electricity. As the earlier discussion indicated, the "evolutionary preparedness" interpretation of this phenomenon has some problematic features. Alternatively, one could argue that phobic cues often share two important qualities, namely unpredictability and uncontrollability and that fear critically depends on these qualities (Merckelbach, van den Hout, \& van der Molen, 1987). This is not a convincing account because it begs the question of why there would be such an invariant connection between these stimulus qualities and fear. Another interpretation of the nonrandom distribution of fears points to the role of culturally transmitted ideas and values about certain phobogenic stimuli (Kirkpatrick, 1984; Davey, 1994b). That is, children might learn from their caregivers that stimuli such as snakes, spiders, and the like are associated with disease, contamination, or dirt. There is strong evidence for the role of disgust in, at least, small animal phobias (Matchett \& Davey, 1991). There are also indications that parents' disgust sensitivity predicts fear of small animals in their offspring (Davey, Forster, \& Mayhew, 1993). These findings fit well with a cultural interpretation of the nonrandom distribution of fears, although they do not rule out genetic transmission of disgust. Clearly, large scale cross-cultural studies are needed to determine the extent that genetic and cultural factors shape the nonrandom distribution of specific fears and phobias.

A third point that deserves further study is the precise time course of specific fears and the factors known to be involved in these fears. Do specific fears occur spontancously and without clear environmental antecedents in children, as Menzies and Clarke (1995) claim? And are subsequent conditioning, modelling, and/or information processes superimposed on these developmental fears responsible for a chronic course of these fears? Or are these processes responsible for the very onset of childhood fears and is it a mix of certain pathways that determines whether specific fears take a chronic course (Ollendick \& King, 1991)? Longitudinal studies are needed to evaluate these possibilities. A longitudinal approach is also required to clarify the role of fundamental personality dimensions in this context. In their recent review, Clark, Watson, and Mineka (1994) conclude that prospective studies on personality variables and anxiety disorders are "puzzlingly rare" (p. 106).

Nearly two decades ago, the Dutch psychologist Barendregt (1976) remarked with regard to phobic disorders that "one fool can think of more hypotheses than ten wise 
men can test" (p. 137). However, since Barendregt, our understanding of specific phobias has advanced to a point wherc the number of problems and sensible hypotheses is limited. Clearly, developing a detailed theoretical framework for explaining specific phobias is not only important in its own right, but may also have considerable heuristic value for our understanding of other anxiety disorders.

\section{REFERENCES}

American Psychological Association. (1994). Diagnostic and statistical manual of mental disonders (4th ed.). Washington, DC: Author.

Agras, S., Sylvester, D., \& Oliveau, D. (1969). The epidemiology of common fears and phobias. Comprehensive Psychiatry, 10, 151-156.

Andrews, G., Stewart, G., Morris-Yates, A., Holt, P., \& Henderson, S. (1990). Evidence for a general neurotic syndrome. British Journal of Psychiatry, 157, 6-12.

Arntz, A., Lavy, E., van den Berg, G., \& van Rijsoort, S. (1993). Negative beliefs of spider phobics: A psychometric evaluation of the spider phobia beliefs questionnaire. Advances in Behaviour Reseanch and Therapy, 15, 257-277.

Arntz, A., Merckelbach, H., \& de Jong, P. J. (1993). Opioid antagonist affects behavioral effects of exposure in vivo. Journal of Consulting and Clinical Psychology, 61, 865-870.

Arntz, A., Rauner, M., \& van den Hout, M. A. (1995). "If I feel anxious, there must be danger": The fallacy of ex consequentia reasoning in inferring danger in anxiety disorders. Behaviour Research and Therapy, 33, 917-925.

Arrindell, W. A., Pickersgill, M. J., Merckelbach, H., Ardon, A. M., \& Cornet, F. C. (1991). Phobic dimensions: III. Factor analytic approaches to the study of common phobic fears: An updated review of findings with adult subjects. Advances in Behaviour Research and Therapy, 13, 73-130.

Barendregt, J. T. (1976). Phobias and phobics. In H. M. van Praag (Ed.), Research in neurosis. Utrecht: Bohn, Scheltema, \& Holkema.

Bauer, D. H. (1976). An exploratory study of developmental changes in children's fears. Journal of Child Psychology and Psychiatry, 17, 69-74.

Beck, A. T., \& Emery, G. (1985). Anxiety disorders and phobias: A cognitive perspective. New York: Basic Books.

Bennett-Levy, J., \& Marteau, T. (1984). Fear of animals: What is prepared? British Journal of Psychology, 75, 37-42.

Bertenthal, B. L., \& Campos, J. J. (1984). A reexamination of fear and its determinants on the visual cliff. Psychophysiology, 21, 413-417.

Biederman, J., Rosenbaum, J., Hirschfeld, D., Faraone, S., Bolduc, E., Gersten, M., Meminger, S., Kagan, J., Snidman, N., \& Reznick, S. (1990). Psychiatric correlates of behavioral inhibition in young children of parents with and without psychiatric disorders. Archives of General Psychiatry, 47, 21-26.

Booth, M. L., Siddle, D. A. T., \& Bond, N. W. (1989). Effects of conditioned fear-relevance and preexposure on expectancy and electrodermal measures of human Pavlovian conditioning. Psychophysiology, 26, 281-291.

Bouton, M. E., \& Swartzentruber, D. (1991). Sources of relapse after extinction in Pavlovian and instrumental conditioning. Clinical Psychology Review, 11, 123-140.

Brewin, C. R., Andrews, B., \& Gotlib, I. H. (1993). Psychopathology and early experience: A reappraisal of retrospective reports. Psychological Bulletin, 113, 82-98.

Burgess, I. S., Jones, L. M., Robertson, S. A., Radcliffe, W. N., \& Emerson, E. (1981). The degree of control exerted by phobic and nonphobic verbal stimuli over the recognition behaviour of phobic and nonphobic subjects. Behaviour Research and Therapy, 19, 233-234.

Cameron, O. G., \& Nesse, R. M. (1988). Systemic hormonal and physiological abnormalities in anxiety disorders. Pyc/wneuroendocrinolugy, 13, 287-307.

Campbell, D., Sanderson, R. E., \& Laverty, S. G. (1964). Characteristics of a conditioned response in human subjects during extinction trials following a single traumatic conditioning trial. Journal of Abnormal and Social Psychology, 68, 627-639.

Chambless, D. L. (1988). Gender and phobia. Gedragstherapie, 21, 283-293.

Chapman, T. F., Fyer, A. J., Mannuzza, S., \& Klein, D. F. (1993). A comparison of treated and untreated simple phobia. American Journal of Psychiatry, 150, 816-818.

Chen, C. N., Wong, J., Lee, N., Chan-Ho, M. W., Lau, J. T. F., \& Fung, M. (1993). The Shatin community mental health survey in Hong Kong. Archives of General Psychiatry, 50, 125-133.

Christianson, S. A. (1992). Emotional stress and eyewitness memory: A critical review. Psychological Bulletin, $112,284-309$. 
Cornelius, R. R., \& Averill, J. R. (1983). Sex differences in fear of spiders. Joumal of Personality and Social Psychalogy, 45, 377-383.

Costello, C. G. (1982). Fears and phobias in women: A community study. Joumal of Abmomal Pychology, 91, 280-286.

Cook, M., \& Mineka, S. (1989). Observational conditioning of fear to fear-relevant versus fear-irrelevant stimuli in rhesus monkeys. Journal of Abnormal Psychology, 98, 448-459.

Clark, L. A., Watson, D., \& Mineka, S. (1994). Temperament, personality, and the mood and anxiety disorders. Journal of Abnormal Psychology, 103, 103-116.

Craske, M. G., Mohlman, J., Yi, J., Glover, D., \& Valeri, S. (1995). Treatment of claustrophobia and snake/spider phobias: Fear of arousal and fear of context. Behaviour Research and Therapy, 33, 197-203.

Dalgleish, T., \& Watts, F. N. (1990). Biases of attention and memory in disorders of anxiety and depression. Clinical Psychology Review, 10, 589-604.

Davey, G. C. L. (1989a). Dental phobics and anxieties: Evidence for conditioning processes in the acquisition and modulation of a learned fear. Behaviour Research and Therapy, 27, 52-58.

Davey, G. C. L. (1989b). UCS revaluation and conditioning models of acquired fears. Behaviour Research and Therapy, 27, 521-528.

Davey, G. C. L. (1992a). Classical conditioning and the acquisition of human fears and phobias: A review and synthesis of the literature. Advances in Behaviour Research and Therapy, 14, 29-66.

Davey, G. C. L. (1992b). Characteristics of individuals with fear of spiders. Anxiety Research 4, 299-314.

Davey, G. C. L. (1994a). Self-reported fears to common indigenous animals in an adult UK population: The role of disgust sensitivity. British Journal of Psychology, 85, 541-554.

Davey, G. C. L. (1994b). The disgusting spider: The role of disease and illness in the perpetuation of fear of spiders. Society and Animals, 2, 17-25.

Davey, G. C. L. (1995). Preparedness and phobias: Specific evolved associations or a generalized expectancy bias. Behavioral and Brain Sciences, 18, 289-325.

Davey, G. C. L., de Jong, P. J., \& Tallis, F. (1993). UCS inflation in the etiology of a variety of anxiety disorders: Some case histories. Behaviour Research and Therapy, 31, 495-498.

Davey, G. C. L., Forster, L., \& Mayhew, G. (1993). Familial resemblances in disgust sensitivity and animal phobias. Behaviour Research and Therapy, 31, 41-50.

Delprato, D. J. (1980). Hereditary determinants of fears and phobias: A critical review. Behavior Therapy, 11 , 79-103.

de Jong, P. J., Merckelbach, H., \& Arntz, A. (1995). Covariation bias in phobic women: The relationship between a priori expectancy, on-line expectancy, autonomic responding, and a posteriori contingency judgement. Journal of Abnormal Psychology, 104, 55-62.

de Jong, P. J., Merckelbach, H., Arntz, A., \& Nijman, H. (1992). Covariation detection in treated and untreated spider phobics. Journal of Abnomal Psychology, 101, 724-727.

de Jong, P. J., Merckelbach, H., Koertshuis, G., \& Muris, P. (1994). UCS inflation and acquires fear responses in human conditioning. Advances in Behaviour Research and Therapy, 16, 131-165.

de Jong, P. J., Merckelbach, H., \& Nijman, H. (1995). Hemisphere preference, anxiety, and covariation bias. Personality and Individual Differences, 18, 363-371.

de Jong, P. J., Muris, P., \& Merckelbach, H. (in press). UCS inflation and human aversive autonomic conditioning. Biological Psychology.

de Jong, P. J., van den Hout, M. A., \& Merckelbach, H. (1995). Covariation bias and the return of fear. Behaviour Research and Therapy, 33, 211-213.

de Jongh, A., Muris, P., Ter Horst, G., \& Duyx, M. (1995). Acquistion and maintenance of dental anxiety: The role of conditioning experiences and cognitive factors. Behaviour Research and Therapy, 33, 205-210.

deSilva, P., \& Rachman, S. (1981). Is exposure a necessary condition for fear-reduction? Beharior Research and Therapy, 19, 227-232.

diNardo, P. A., Guzy, L. T., \& Bak, R. M. (1988). Anxiety response patterns and etiological factors in dogfearful and nonfearful subjects. Behaviour Research and Therapy, 26, 245-252.

Doogan, S., \& Thomas, G. V. (1992). Origins of fear of dogs in adults and children: The role of conditioning processes and prior familiarity with dogs. Behaviour Research and Therapy, 30, 387-394.

Eifert, G. H., \&c Wilson, P. H. (1991). The triple response approach to assessment: A conceptual and methodological reappraisal. Behaviour Research und Therapy, 29, 283-292.

Errera, P. (1962). Some historical aspects of the concept phobia. Psychiatric Quarterly, 36, 325-336.

Eysenck, H. J. (1979). The conditioning model of neurosis. Behavioral and Brain Sciences, 2, 155-199.

Eyscnck, M. W. (1992). Anxiety: The cognitive perspective. Hillsdale NJ: Erlbaum.

Fredrikson, M., Annas, P., Fischer, H., \& Wik, G. (1996). Gender and age differences in the prevalence of specific fears and phobias. Behaviour Research and Therapy, 34, 33-39.

Fredrikson, M., Wik, G., Annas, P., Ericson, K, \& Stone-Elander, S. (1995). Functional neuroanatomy of visually elicited simple phobic fear: Additional data and theoretical analysis. Psychophysiology, 32, 43-48. 
Fredrikson, M., Wik, G., Greitz, T., Eriksson, L., Stone-Elander, S., Ericson, K. \& Sedvall, G. (1993). Regional cerebral blood flow during experimental phobic fear. Psychophysiology, 30, 126-130.

Fyer, A. J., Mannuzza, S., Gallops, M. S., Martin, L. Y., Aaronson, C., Gorman, J. M., Liebowitz, M. R., \& Klein, D. F. (1990). Familial transmission of simple phobias and fears. Archives of General Psychiatry, 47, 252-256.

Green, G., \& Osborne, J. G. (1985). Does vicarious instigation provide support for observational learning theories? Psychological Bulletin, 97, 3-17.

Greenberg, D. B., Stern, T. A., \& Weilburg, J. B. (1988). The fear of choking: Three successfully treated cases. Psychosomatics, 29, 126-129.

Hedlund, M. A., \& Chambless, D. L. (1987). Sex differences in aversive conditioning: A comparison of women at different phases of the menstrual cycle with men. Paper presented at the meeting of the Eastern Psychological Association, Arlington, VA.

Heller, W., Etienne, M. A., \& Miller, G. A. (1995). Patterns of perceptual asymmetry in depression and anxiety: Implications for neuropsychological models of emotion and psychopathology. Joumal of Abnormal Psychology, 104, 327-333.

Himle, J. A., Crystal, D., Curtis, G. C., \& Fluent, T. E. (1991). Mode of onset of simple phobia subtypes: Further evidence of heterogeneity. Psychiatry Research, 36, 37-43.

Hugdahl, K (1981). The three-systems-model of fear and emotion: A critical examination. Behaviour Research and Therapy, 19, 75-85.

Hugdahl, K. (1989). Simple phobias. In G. Turpin (Ed.), Handbook of clinical psychophysiology. Chichester: Wiley.

Hygge, S., \& Ōhman, A. (1978). Modeling processes in the acquisition of fears: Vicarious electrodermal conditioning to fear-relevant stimuli. Journal of Personality and Individual Differences, 36, 271-279.

Jacobs, W. J., \& Nadel, L. (1985). On stress induced recovery of fears and phobias. Psychological Review, 92, 512-531.

Kagan, J. (1983). Stress and coping in early development. In N. Garmezy \& M. Rutter (Eds.), Stress, coping, and development in children. New York: McGraw-Hill.

Kalin, N. H. (1993). The neurobiology of fear. Scientific American, 265, 54-60.

Kelley, M. J. (1987). Hormones and clinical anxiety: An imbalanced neuromodulation of attention. In $\mathbf{H}$. J. Eysenck \& I. Martin (Eds.), Theoretical foundations of behavior therapy. New York: Plenum Press.

Kendler, K. S., Neale, M. C., Kessler, R. C., Heath, A. C., \& Eaves, L. J. (1992). The genetic epidemiology of phobias in women: The interrelationship of agoraphobia, situational phobia, and simple phobia. Archives of General Psychiatry, 49, 273-281.

Kessler, R. C., McGonagle, K. A., Zhao, S., Nelson, C. B., Hughes, M., Eshleman, S., Wittchen, H. U., \& Kendler, K. S. (1994). Lifetime and 12-month prevalence of DSM-III-R psychiatric disorders in the Unitcd States. Archives of General Psychiatry, 51, 8-19.

Kheriaty, E., Kleinknecht, R. A., \& Hyman, I. E. (in press). Recall and validation of phobia origins as a function of a structured interview versus the Phobic Origins Questionnaire. Behaxior Modification.

Kindt, M., Bierman, D., \& Brosschot, J. F. (1996). Cognitive bias in spider phobic and nonphobic children. Manuscript submitted for publication.

Kirkby, K. C., Menzies, R. G., Daniels, B. A., \& Smith, K. L. (1995). Aetiology of spider phobia: Classificatory differences between two origins instruments. Behaviour Research and Therapy, 33, 955-958.

Kirkpatrick, D. R. (1984). Age, gender and patterns of common intense fears among adults. Behaviour Research and Therapy, 22, 141-150.

Kirsch, P., \& Boucsein, W. (1994). Electrodermal conditioning with prepared and unprepared stimuli. Integrative Physiological and Behavioral Science, 29, 134-140.

Kleinknecht, R. A. (1994). Acquistion of blood, injury, and needle fears and phobias. Behaviour Research and Therapy, 32, 817-823.

Kuch, K., Cox, B. J., Evans, R. E., \& Shulman, I. (1994). Phobias, panic, and pain in 55 survivors of road vehicle accidents. Journal of Anxiety Disonders, 8, 181-187.

Lang, P. J. (1968). Fear reduction and fear behavior: Problems in treating a construct. In J. M. Schlien (Ed.), Research in psychotherapy (Vol. III). Washington, DC: APA.

Lapouse, R., \& Monk, M. A. (1959). Fears and worries in a representative sample of children. American Journal of Onthopsychiatry, 29, 803.

Lautch, H. (1971). Dental phobia. British Journal of Psychiatry, 119, 151-158.

Lavy, E. H., van den Hout, M. A., \& Arntz, A. (1993). Attentional bias and spider phobia. Conceptual and clinical issues. Behaviour Research and Therapy, 31, 17-24.

LeDoux, J. (1992). Emotion as memory: Anatomical systems underlying indelible neural traces. In S. A. Christianson (Ed.), The handbook of emotion and memory: Research and theory. Hillsdale, NJ: Erlbaum.

Logan, A. C., \& Goetsch, V. L. (1993). Attention to external threat cues in anxiety states. Clinical Psychology Review, 13, 541-559. 
MacFarlane, J. W., Allen, L., \& Honzik, M. P. (1954). A developmental study of the behavior problems of normal children between 21 months and 14 years. Berkeley, CA: University of California Press.

Macleod, C. M. (1991). Half a century of research on the Stroop effect: An integrative review. Psychological Bulletin, 109, 163-203.

MacLeod, C., \& Hagan, R. (1992). Individual differences in the selective processing of threathening information and emotional responses to a stressful life event. Behaviour Research and Therapy, 30, 151-161.

Malloy, P., \& Levis, D. J. (1988). A laboratory demonstration of persistent human avoidance. Behavior Therapy, 19, 229-241.

Marks, I. (1987). Fears, phobias, and rituals. Oxford: Oxford University Press.

Marks, I. (1988). Blood-injury phobia: A review. American Journal of Psychiatry, 145, 1207-1213.

Marks, I., \& Nesse, R. M. (1994). Fear and fitness: An evolutionary analysis of anxiety disorders. Ethology and Sociobiology, 15, 247-261.

Matchett, G., \& Davey, G. C. L. (1991). A test of a disease avoidance model of animal phobias. Behavionur Research and Therapy, 29, 91-94.

McNally, R. J. (1987). Preparedness and phobias: A review. Psychological Bulletin, 101, 283-303.

McNally, R. J. (1989). On "stress-induced recovery of fears and phobias." Psychological Review, 96, 180-181.

McNally, R. J. (1995a). Preparedness, phobias, and the Panglossian paradigm. Behavioral and Brain Sciences, $18,303-304$.

McNally, R. J. (1995b). Automaticity and the anxiety disorders. Behaviour Reseanch and Therapy, 33, 747-754.

McNally, R. J., \& Foa, E. B. (1986). Preparedness and resistance to extinction to fear-relevant stimuli: A failure to replicate. Behaviour Research and Therapy, 24, 529-535.

Menzies, R. G., \& Clarke, J. C. (1993a). The etiology of fear of heights and its relationship to severity and individual response patterns. Behaviour Research and Therapy, 31, 355-366.

Menzies, R. G., \& Clarke, J. C. (1993b). The etiology of childhood water phobia. Behaviour Research and Therapy, 31, 499-501.

Menzies, R. G., \& Clarke, J. C. (1994). Retrospective studies of the origins of phobias: A review. Anxiety, Stress, and Coping, 7, 305-318.

Menzies, R. G., \& Clarke, J. C. (1995). The etiology of phobias: A nonassociative account. Clinical Psychology Review, 15, 23-48.

Merckelbach, H., Arntz, A., \&c de Jong, P. J. (1991). Conditioning experiences in spider phobics. Behaviour Research and Therapy, 29, 335-335.

Merckelbach, H., Arntz, A., de Jong, P. J., \& Schouten, E. (1993). Effects of endorphin blocking on conditioned SCR in humans. Behaviour Research and Therapy, 31, 775-779.

Merckelbach, H., Arrindell, W. A., Arntz, A., \& de Jong, P. J. (1992). Pathways to spider phobia. Behaviour Research and Therapy, 30, 543-546.

Merckelbach, H., \& de Jong, P. J. (1996). Evolutionary models of phobias. In G. C. L. Davey (Ed.), Phobias: $A$ handbook of description, treatment, and theory. Chichester: Wiley.

Merckelbach, H., de Jong, P. J., Arntz, A., \& Schouten, E. (1993). The role of evaluative learning and disgust sensitivity in the etiology and treatment of spider phobia. Advances in Behaviour Research and Therapy, 15, 243-255.

Merckelbach, H., Muris, P., \& de Jong, P. J. (1990). Hemisphere preference, phobia, and depression. International Journal of Neuroscience, 55, 119-123.

Merckelbach, H., van den Hout, M. A., \& van der Molen, G. M. (1987). Fear of animals: Correlations between fear ratings and perceived characteristics. Psychological Reports, 60, 1203-1209.

Merluzzi, T. V., Tayłor, C. B., Boltwood, M., \& Götestam, K. G. (1991). Opioid antagonist impedes exposure. Journal of Consulting and Clinical Psychology, 59, 425-430.

Milgrom, P., Mancl, L., King, B., \& Weinstein, P. (1995). Origins of childhood dental fear. Behaviour Reseanch and Therapy, 33, 313-319.

Mineka, S. (1985). Animal models of anxiety-based disorders: Their usefulness and limitations. In A. H. Tunla, \& J. Maser (Eds.), Anxiety arul the anxiety disenders. Hillsdale, NJ: Erlbaun.

Mineka, S. (1987). A primate model of phobic fears. In H. J. Eysenck \& I. Martin (Eds.), Theonetical foundations of behavior therapy. New York: Plenum Press.

Mineka, S., \& Cook, M. (1993). Mechanisms involved in the observational conditioning of fear. Journal of Experimental Psychology: General, 122, 23-38.

Mineka, S., \& Sutton, S. K. (1992). Cognitive biases and emotional disorders. Psychological Science, 3, 65-69.

Moore, R., Brodsgaard, I., \& Birn, H. (1991). Manifestations, acquisition, and diagnostic categories of dental fear in a self-referred population. Behaviour Research and Therapy, 29, 51-60.

Mowrer, O. (1960). Learning theory and behaviour. New York: Wiley.

Mulkens, A. A. N., de Jong, P. J., \& Merckelbach, H. (in press). Disgust sensitivity: A vulnerability factor for spider phobia. Journal of Abnormal Psychology. 
Muris, P., Steerneman, P., Merckelbach, H., \& Meesters, C. (1996). Parental modelling and fearfulness in middle childhood. Behaviour Research and Therapy, 34, 265-268.

Myers, J. K., Weissman, M. M., Tischler, G. L., Holzer, C. E., Orvaschel, H., Anthony, J. C., Boyd, J. H., Burke, J. D., Kramer, M., \& Stoltzman, R. (1984). Six-month prevalence of psychiatric disorders in three communities, 1980 to 1982 . Archives of General Psychiatry, 41, 959-967.

Öhman, A. (1986). Face the beast and fear the face: Animal and social fears as prototypes for evolutionary analyses of emotion. Psychophysiology, 23, 123-145.

Ōhman, A. (1987). Evolution, learning, and phobias. In D. Magnusson \& A. Ōhman (Eds.), Psychopathology: An interactional perspective. New York: Academic Press.

Öhman, A. (1993). Fear and anxiety as emotional phenomena: Clinical phenomenology, evolutionary perspectives, and information processing mechanisms. In M. Lewis \& J. M. Haviland (Eds.), Handbook of emotions. New York: Guilford Press.

Öhman, A., \& Soares, J. J. F. (1994). Unconscious anxiety: Phobic responses to masked stimuli. Journal of Abnormal Psychology, 103, 231-240.

Ollendick, T. II. (1979). Fear reduction techniques with children. In P. Miller \& R. Eisler (Eds.), Progness in behavior modification (Vol. 8). New York: Academic Press.

Ollendick, T. H., \& King, N. J. (1991). Origins of childhood fears: An evaluation of Rachman's theory of fear acquisition. Behaviour Research and Therapy, 29, 117-123.

Öst, L. G. (1987a). Age of onset in different phobias. Journal of Abnormal Psychology, 96, 223-229.

Öst, L. G. (1987b). Individual response patterns and the effect of different behavioural methods in the treatment of phobias. In D. Magnusson \& A. Ōhman (Eds.), Psychopathology: An interactional perspective. New York: Academic Press.

Öst, L. G. (1989). One-session treatment for specific phobias. Behaviour Reseanch and Therapy, 27, 1-8.

Öst, L. G. (1991). Acquisition of blood and injection phobia and anxiety response patterns in clinical patients. Behaviour Research and Therapy, 29, 323-332.

Öst, L. G., \& Hugdahl, K. (1981). Acquisition of phobias and anxiety response patterns in clinical patients. Behaviour Research and Therapy, 19, 439-447.

Packer, J. S., Clark, B. M., Bond, N. W., \& Siddle, D. A. T. (1991). Conditioning with facial expression of emotion: A comparison of aversive and nonaversive unconditioned stimuli. Journal of Psychophysiology, 5, 79-88.

Page, A. C. (1994). Blood-injury phobia. Clinical Pyychology Review, 14, 443-461.

Philips, K., Fulker, D. W., \& Rose, R. J. (1987). Path analysis of seven fear factors in adult twin and sibling pairs and their parents. Genetic Epidemiology, 4, 345-355.

Pratto, F., \& John, O. P. (1991). Automatic vigilance: The attention grabbing power of negative social information. Joumal of Personality and Social Psychology, 61, 380-391.

Rachman, S. (1976). The passing of the two-stage theory of fear and avoidance: Fresh possibilies. Behaviour Research and Therapy, 14, 125-134.

Rachman, S. (1977). The conditioning theory of fear acquisition: A critical examination. Behaviour Research and Therapy, 15, 375-387.

Rachman, S. (1989). The return of fear. Clinical Psychology Review, 9, 147-168.

Rachman, S. (1990a). Fear and courage. New York: Freeman.

Rachman, S. (1990b). The determinants and treatment of simple phobias. Advances in Behaviour Research and Therapy, 12,1-30.

Rachman, S. (1991). Neoconditioning and the classical theory of fear acquistion. Clinical Psychology Review, $11,155-173$.

Rachman, S., Craske, M., Tallman, K., \& Solyom, C. (1986). Does escape behavior strengthen agoraphobic avoidance? A replication. Behavior Therapy, 17, 366-384.

Rachman, S., \& Cuk, M. (1992). Fearful distortions. Behaviour Research and Therapy, 30, 583-589.

Regier, D. A., Boyd, D. H., Burke, J. D., Rae, D. S., Myers, J. K., Kramer, M., Robins, L. N., George, L. K., Karno, M., \& Locke, B. Z. (1988). One-month prevalence of mental disorders in the United States. Archives of General Psychiatry, 45, 977-986.

Reiss, S. (1980). Pavlovian conditioning and human fear: An expectancy model. Behavior Therapy, 11, 380-396.

Renner, F. (1990). Spinnen: Ungeheuer sympatisch. Kaiserslautern: R. Nitsche Verlag.

Rescorla, R. A. (1971). Variations in the effectiveness of reinforcement and nonreinforcement following prior inhibiting conditioning. Learning and Motivation, 2, 113-123.

Riskind, J. H., Moore, R., \& Bowley, L. (1995). The looming of spiders: The fearful perceptual distortions of movement and menace. Behaziour Research and Therapy, 33, 171-178.

Saigh, P. A. (1984). Pre- and postinvasion anxiety in the Lebanon. Behavior Therapy, 15, 185-190.

Seligman, M. E. P. (1971). Phobias and preparedness. Behavior Therapy, 2, 307-320. 
Speltz, M. L., \& Bernstein, D. A (1976). Sex differences in fearfulness: Verbal report, overt avoidance, and demand characteristics. Journal of Behavior Therafy and Experimental Psychiatry, 7, 177-182.

Streblow, H., Hoffman, J., \& Kasielke, E. (1985). Experimentalpsychologische Analyse von Gedächtnisprozesse bei Phobikern. Zeitschrift für Psychologie, 193, 147-161.

Stevenson, J., Batten, N., \& Cherner, M. (1992). Fears and fearfulness in children and adolescents: A genetic analysis of twin data. Journal of Child Psychology and Psychiatry, 33, 977-985.

Sturgis, E. T., \& Scott, R. (1984). Simple phobia. In S. M. Turner (Ed.), Behavioral theories and treatment of anxiety. New York: Plenum Press.

Thorpe, S. J., \& Salkovskis, P. M. (1995). Phobic beliefs: Do cognitive factors play a role in specific phobias? Behaviour Research and Therapy, 33, 805-816.

Thyer, B. A., Himle, J., \& Curtis, G. C. (1985). Blood-injury-illness phobia: A review. Journal of Clinical Psychology, 41, 451-459.

Tomarken, A. J., Mineka, S., \& Cook, M. (1989). Fear relevant selective associations and covariation bias. Journal of Abnormal Psychology, 98, 381-394.

Tomarken, A. J., Sutton, S. K., \& Mineka, S. (1995). Fear-relevant illusory correlations: What types of associations promote judgmental bias? Journal of Abnormal Psychology, 104, 312-326.

Tucker, D. M., \& Newman, J. P. (1981). Verbal versus imaginal cognitive strategies in the inhibition of emotional arousal. Cognitive Therapy and Reseanch, 5, 197-202.

van den Hout, M. A., \& Merckelbach, H. (1991). Classical conditioning: Still going strong. Behavioural Psychotherapy, 19, 59-79.

van der Molen, G. M., Merckelbach, H., \& van den Hout, M. A. (1988). The possible relation of the menstrual cycle to susceptibility to fear acquisition. Journal of Behavior Therapy and Experimental Psychiatry, 19, $127-133$.

Villa, G., \& Beech, H. R. (1977). Vulnerability and conditioning in relation to the human menstrual cycle. British Journal of Social and Clinical Psychology, 16, 69-75.

Ware, J., Jain, K., Burges, I., \& Davey, G. C. L. (1994). Disease-avoidance model: Factor analysis of common animal fears. Behaviour Research and Therapy, 32, 57-63.

Watson, J., \& Rayner, R. (1920). Conditioned emotional reactions. Journal of Experimental Psychology, 3, 1-22.

Watson, D., Clark, L. A., \& Carey, G. (1988). Positive and negative affect and their relation to anxiety and depressive disorders. Journal of Almormal Psychology, 97, 346-353.

Watts, F. N., Trezise, L., \& Sharrock, R. (1986). Processing of phobic scimuli. British Journal of Clinical Psychology, 25, 253-259.

Webb, K. \& Davey, G. C. L. (1992). Disgust sensitivity and fear of animals: Effect of exposure to violent or rcvulsive matcrial. Anxiety, Stress, and Coping, 5, 329-335.

White, K., \& Davey, G. C. L. (1989). Sensory preconditioning and UCS inflation in human fear conditioning. Behaviour Research and Therapy, 27, 161-166.

Wik, G., Fredrikson, M., Ericson, K, Ericksson, L., Stone-Elander, S., \& Greitz, T. (1993). A functional cerebral response to frightening visual stimulation. Psychiatry Research (Neuroimaging), 50, 15-24.

Withers, R. D., \& Deane, F. P. (1995). Origins of common fears: Effects on severity, anxiety responses, and memories of onset. Behaviour Research and Therapy, 33, 903-915.

Wittchen, H. (1988). Natural course and spontaneous remissions of untreated anxiety disorders. In I. Hand \& H. Wittchen (Eds.), Panic and phobias: Treatments and variables affecting course and outcome. Berlin: Springer Verlag.

Wolpe, J. (1981). The dichotomy between classical conditioned and cognitively leardned anxiety. Journal of Behavior Therapy and Experimental Psychiatry, 12, 35-42.

Wolpe, J., Lande, S. D., McNally, R. J., \& Schotte, D. (1985). Differentiation between classically conditoned and cognitively based neurotic fears: Two pilot studies. Joumal of Behavior Therapy and Experimental Psychiatry, $12,35-42$. 